\title{
Variability in the management and outcomes of extremely preterm births across five European countries: a population-based cohort study
}

\author{
Lucy K Smith, ${ }^{1}$ Beatrice Blondel, ${ }^{2}$ Patrick Van Reempts, ${ }^{3}$ Elizabeth S Draper, ${ }^{1}$ \\ Bradley N Manktelow, ${ }^{1}$ Henrique Barros, ${ }^{4}$ Marina Cuttini, ${ }^{5}$ Jennifer Zeitlin, ${ }^{2}$ \\ for the EPICE Research Group
}

'Department of Health Sciences, University of Leicester, Leicester, UK

${ }^{2}$ Obstetrical, Perinatal and Pediatric Epidemiology Research Team (Epopé), Inserm UMR 1153, Center for Epidemiology and Statistics Sorbonne Paris Cité, DHU Risks in pregnancy, Paris Descartes University, Paris, France

${ }^{3}$ Department of Neonatology, Antwerp University Hospital, University of Antwerp, Antwerp and Study Centre for Perinatal Epidemiology Flanders, Brussels, Belgium

${ }^{4}$ EPIUnit-Institute of Public Health, University of Porto, Porto, Portugal

${ }^{5}$ Clinical Care and Management Innovation Research Area, Bambino Gesù Children's Hospital, IRCCS, Rome, Italy

Correspondence to Dr Lucy K Smith, The Infant Mortality and Morbidity Studies (TIMMS), Department of Health Sciences, College of Medicine, Biological Sciences and Psychology, University of Leicester, Centre for Medicine, University Road, Leicester, LE1 7RH, UK; Iks1@leicester.ac.uk

Received 4 October 2016 Accepted 16 January 2017 Published Online First 23 February 2017

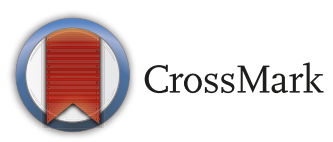

To cite: Smith LK, Blondel $B$, Van Reempts P, et al. Arch Dis Child Fetal Neonatal Ed 2017:102:F400-F408.

\section{ABSTRACT}

Objective To explore international variations in the management and survival of extremely low gestational age and birthweight births.

Design Area-based prospective cohort of births Setting 12 regions across Belgium, France, Italy, Portugal and the UK

Participants 1449 live births and fetal deaths between $22^{+0}$ and $25^{+6}$ weeks gestation born in 2011-2012.

Main outcome measures Percentage of births; recorded live born; provided antenatal steroids or respiratory support; surviving to discharge (with/without severe morbidities).

Results The percentage of births recorded as live born was consistently low at 22 weeks and consistently high at 25 weeks but varied internationally at 23 weeks for those weighing $500 \mathrm{~g}$ and over (range 33\%-70\%) and at 24 weeks for those under $500 \mathrm{~g}$ (range 5\%-71\%). Antenatal steroids and provision of respiratory support at 22-24 weeks gestation varied between countries, but were consistently high for babies born at 25 weeks. Survival to discharge was universally poor at 22 weeks gestation (0\%) and at any gestation with birth weight $<500 \mathrm{~g}$, irrespective of treatment provision. In contrast, births at 23 and 24 weeks weighing $500 \mathrm{~g}$ and over showed significant international variation in survival (23 weeks: range: $0 \%-25 \%$; 24 weeks range: $21 \%-50 \%$ ), reflecting levels of treatment provision.

Conclusions Wide international variation exists in the management and survival of extremely preterm births at 22-24 weeks gestation. Universally poor outcomes for babies at 22 weeks and for those weighing under $500 \mathrm{~g}$ suggest little impact of intervention and support the inclusion of birth weight along with gestational age in ethical decision-making guidelines.

\section{INTRODUCTION}

Advances in antenatal and neonatal care of very preterm birth have significantly improved the survival of babies who were once seen as non-viable. ${ }^{1-4}$ Consequently, reconsideration of the limits of viability has been called for. ${ }^{5}$ However, high rates of severe morbidity associated with survival at very early gestational age raise difficult ethical and policy questions when determining management policy, counselling parents and deciding whether to initiate intensive care. ${ }^{36-8}$

\section{What is already known on this topic?}

Large international differences exist in reported rates of extremely preterm and very low birthweight births.

- Variation in survival rates at extremely low gestational age and extremely low birth weight make counselling parents and decisions to initiate treatment difficult.

\section{What this study adds?}

Wide international variation exists in the management of babies born at the limits of viability, which impacts on survival and makes international comparison of survival outcomes problematic.

- Birth weight should be included within ethical guidelines for counselling parents and making decisions around intensive treatment for births before 25 weeks.

Wide regional and international differences in reported survival rates of extremely preterm births make these decisions more challenging, as a lack of consistent outcome data at early gestations prevent clear identification of criteria for intervention. The range of definitions of periviable birth has led to differences in the reported prevalence, ${ }^{9}$ and is likely to contribute to these wide international variations in reported survival rates. ${ }^{10}$ The definition of viability based on gestational age, birth weight and other factors may be influenced by variation in national legal registration criteria, ${ }^{11} 12$ and clinical guidelines overlaid by clinicians' perceived risk and parental opinions. ${ }^{13}$ This will also lead to variations in the initiation and continuation of intensive care $^{10}$ and may impact on eligibility criteria for maternity and paternity benefits and funeral costs.

Currently, little evidence exists regarding the impact of increased intensity of intervention on short-term and long-term outcomes, particularly survival free of major morbidities. According to Lantos and Meadow, ${ }^{14}$ policies that limit medical intervention in extremely preterm infants lead to low survival rates that further corroborate these 
policies and perpetuate the poor outcomes. In the Netherlands, the national policy of non-resuscitation $<25$ weeks gestation has recently been reviewed on the basis of technological progress and results published in the literature. ${ }^{15}$

Using the data of a large European population-based study of extremely preterm births, we explore international differences in the frequency of recording of births as live born, provision of active treatment and subsequent survival by gestational age and birth weight, across 12 regions in five countries.

\section{METHODS}

The Effective Perinatal Intensive Care in Europe (EPICE) study is an international area-based study aimed at assessing the use of evidence-based interventions for very preterm births. ${ }^{16}$ The study recruited a cohort of all stillbirths and live births from $22^{+0}$ to $31^{+6}$ weeks of gestation that occurred over 12 months in the period between April 2011 to June 2012 in 19 European regions (except in France where data were collected for 6 months) for a total of 7336 cases covering over 850000 annual births. Data were abstracted from medical records in obstetric and neonatal units using a standardised questionnaire with common pretested definitions. Gestational age was defined as the best obstetric assessment, using information on last menstrual period and routine ultrasound measures. Infants were followed-up until discharged home from hospital or into longterm care or death.

Parental consent and ethics and data protection approval was obtained in each study region as required by national legislation.

For this study, we used the data of all reported stillbirths and live births between $22^{+0}$ and $25^{+6}$ weeks of gestation, with known information on birth weight at delivery and outcome at discharge. We excluded terminations of pregnancy. Analyses were undertaken for gestation-specific $\left(22^{+0}-22^{+6} ; 23^{+0}-23^{+6}\right.$; $24^{+0}-24^{+6}$ and $25^{+0}-25^{+6}$ weeks) and birth weight-specific $(<500 \mathrm{~g} ; \geq 500 \mathrm{~g})$ groups. The EPICE regions were combined by country, including only those countries with five or more births in each gestational age and birthweight group to allow appropriate comparisons. This resulted in the inclusion of 12 regions across 5 countries: Flanders, Belgium; Burgundy, Ile-de-France and Northern regions, France; Emilia-Romagna, Lazio and Marche regions, Italy; Lisbon and Northern regions, Portugal; East Midlands, Northern and Yorkshire and Humber regions, UK. Although the official criteria for registration of stillbirths and live births may differ between these countries (table 1), the use of the common EPICE recruitment criteria allowed to overcome these differences and provide comparable data across the five countries.

Table 1 Official gestational age and birthweight criteria* for registration of live births and stillbirths by country

\begin{tabular}{lll}
\hline & Stillbirths & Live births \\
\hline Belgium & $\geq 25^{+5}$ weeks & No limit \\
France & $\geq 22^{+0}$ weeks or $\geq 500 \mathrm{~g}$ & $\geq 22$ weeks or \\
& & $\geq 500 \mathrm{~g}$ \\
Italy & $\geq 25^{+5}$ weeks & No limit \\
Portugal & $\geq 24^{+0}$ weeks or $>500 \mathrm{~g}$ if gestational age & No limit \\
& unknown & No limit \\
UK & $\geq 24^{+0}$ weeks & \\
\hline *These may differ from gestational age and birthweight limits for the statistical \\
recording of live births and stillbirths in some countries.
\end{tabular}

\section{Data analysis}

The percentage of births reported as live born was calculated for each country, gestational age and birthweight group based on the number of live births divided by the total number of stillbirths and live births in that group. Here, provisions of antenatal steroids and of respiratory support (ie, any continuous positive airway pressure or mechanical ventilation) were used as indicators of whether the baby was viewed as viable before and after birth, respectively. Survival outcomes were divided into four hierarchical groups: death before discharge; survival to discharge with severe neonatal morbidity (comprising intraventricular haemorrhage grade III or IV, cystic periventricular leukomalacia, retinopathy of prematurity stages III-V or severe necrotising enterocolitis); survival to discharge with bronchopulmonary dysplasia (BPD) (defined by receiving oxygen at 36 weeks gestation) or survival without any of these severe morbidities. BPD was assessed separately because there is large regional variability in respiratory management and accepted oxygen saturation targets which can affect measurement of this variable. ${ }^{17}$ Information on the fraction of inspired oxygen $\left(\mathrm{FiO}_{2}\right)$ that would have allowed standardisation were not available in all regions. For the sake of comparability between countries and across outcome indicators, unless stated differently the denominator used throughout was the number of all births (stillbirths and live births by gestational age and birthweight group in each country), as while this may seem counterintuitive for measures such as respiratory support (since only live births would receive this type of care), it improves the comparability between countries where there are differences in whether a birth is reported as live or not.

The $\chi^{2}$ tests were performed to assess whether the outcome measures varied significantly between countries.

Sensitivity analyses were undertaken excluding those fetuses known to have died in the antepartum period since death could have occurred several days before delivery leading to a decrease in birth weight. Since the results were qualitatively the same, only the analyses of all births are presented here.

\section{RESULTS}

There were 1500 births between $22^{+0}$ and $25^{+6}$ weeks gestation across the 5 countries, of which 51 were excluded due to missing birth weight (3.4\%) leaving 1449 births for analysis. The rates of birth at 22-25 weeks gestation were similar across all five countries (table 2) at 2.8 per 1000 births (range: 2.4 in Italy to 3.0 in France).

\section{Recording of births as live born}

The percentage of births recorded as live born increased with increasing gestation and birth weight (figure 1 and table 3), but this trend varied between countries. There was a consistently low percentage recorded as live born for all births at 22 weeks gestation (<500 g: 12.8\%; $\geq 500 \mathrm{~g}$ : $24.5 \%$ ) (figure 1A) and for those at 23 weeks weighing $<500 \mathrm{~g}(18.2 \%)$ (figure 1B). In contrast, there was a significantly varied approach for births at 23 weeks gestation and birth weight $500 \mathrm{~g}$ and over, with the UK and Italy having higher percentages of births recorded as live born (69.6\% and 59.2\%, respectively) than in France, Belgium and Portugal (33.3\% for all) (figure 1B). Similarly, there was a variation in approach to babies born at 24 weeks gestation weighing $<500 \mathrm{~g}$ with the lowest rates in France $(5.0 \%)$ and the UK (12.5\%) compared with Italy $(71.4 \%)$ (figure 1C). 
Original article

Table 2 Number and rate of births at 22-25 weeks gestational age in 5 European countries (based on data from 12 regions)

\begin{tabular}{|c|c|c|c|c|c|c|c|}
\hline \multirow[b]{3}{*}{ Countries* } & \multirow[b]{3}{*}{ All gestations } & \multirow[b]{3}{*}{ 22-25 weeks } & \multicolumn{4}{|c|}{ Number of births } & \multirow{3}{*}{$\begin{array}{l}\text { Rate of births } 22-25 \text { weeks per } \\
1000 \text { total births }(95 \% \mathrm{Cl})\end{array}$} \\
\hline & & & \multicolumn{2}{|c|}{$22-23$ weeks } & \multicolumn{2}{|c|}{$24-25$ weeks } & \\
\hline & & & $<500 \mathrm{~g}$ & $\geq 500 \mathrm{~g}$ & $<500 \mathrm{~g}$ & $\geq 500 \mathrm{~g}$ & \\
\hline Belgium & 69395 & 201 & 34 & 51 & 14 & 102 & 2.90 (2.51 to 3.33 ) \\
\hline Francet & 132683 & 399 & 86 & 105 & 28 & 180 & 3.01 (2.72 to 3.32 ) \\
\hline Italy & 108679 & 266 & 59 & 65 & 14 & 128 & 2.44 (2.16 to 2.76 ) \\
\hline Portugal & 61017 & 158 & 32 & 26 & 14 & 86 & 2.59 (2.20 to 3.03$)$ \\
\hline UK & 149241 & 425 & 73 & 73 & 28 & 251 & 2.85 (2.58 to 3.13$)$ \\
\hline Total & 521215 & 1449 & 284 & 320 & 98 & 747 & 2.78 (2.64 to 2.93 ) \\
\hline
\end{tabular}

*Regions comprise: Belgium (Flanders); France (Burgundy, Ile-de-France, Northern); Italy (Emilia Romagna, Lazio, Marche); Portugal (Northern region, Lisbon); UK (East Midlands, Northern, Yorkshire).

tStudy period: 12 months except France 6 months, 6 January 2011-5 May 2012, except France.

There was a consistently higher percentage recorded live born for births at 24 and 25 weeks gestation weighing over $500 \mathrm{~g}$ (74.1\% and 79.8\%, respectively) (figure $1 \mathrm{C}, \mathrm{D})$.

\section{Initiation of medical treatment}

For babies born at 22 weeks gestation, the percentage of all births associated with antenatal steroids prophylaxis (table 3) was consistently very low (2\%) for those weighing $<500 \mathrm{~g}$ (figure 1A), while there were significant differences for births weighing $500 \mathrm{~g}$ and over ranging from $25 \%$ of births in Italy to $0 \%$ in the UK, France and Belgium. At 23 weeks gestation, the rate of prophylaxis increased to $16 \%$ for births $<500 \mathrm{~g}$ with no significant differences between countries, but again there was variation for births $\geq 500 \mathrm{~g}$ (from $0 \%$ in Belgium to $58 \%$ in Italy and the UK). Rates were higher in all countries at 24 and 25 weeks gestation, but significant variability persisted for birth weights $\geq 500 \mathrm{~g}$, with France and Belgium having consistently lower rates of provision.

Respiratory support at 22 weeks gestation (figure $1 \mathrm{~A}$ and table 3) varied significantly internationally for both birthweight groups with no interventions in Belgium, France and the UK compared with Italy (<500 g: 9\%; $\geq 500 \mathrm{~g}: 25 \%)$ and Portugal (<500 g: 0\%; $\geq 500 \mathrm{~g}: 13 \%)$. This variation in approach persisted at 23 and 24 weeks gestation (figure 1B, C). Italy had consistently high rates of initiation of respiratory support than the other countries, while France had the lowest rates. For babies born at 25 weeks gestation, the rates of initiation of treatment were substantially higher particularly for those born weighing $500 \mathrm{~g}$ or over and were consistent across the five countries (range: 72\%-82\%) (figure 1D).

\section{Survival to discharge}

Survival to discharge was universally poor across all five countries for babies born at 22 weeks gestation $(0.0 \%$ for both $<500$ and $\geq 500 \mathrm{~g}$ ) (figure 1A) and for all births at 23, 24 and 25 weeks gestation weighing $<500 \mathrm{~g}(1 \%, 2 \%$ and $7 \%$, respectively) (figure 1B-D) irrespective of variations in the medical treatment provided to these babies. However, at 23 and 24 weeks gestation for babies weighing over $500 \mathrm{~g}$ there was significant variation between countries in survival to discharge, ranging from $0 \%$ to $25 \%$ of all births at 23 weeks and $21 \%$ $50 \%$ at 24 weeks gestation (figure $1 \mathrm{~B}, \mathrm{C}$ ). Those countries with higher rates of respiratory support and antenatal steroid provision had generally higher levels of survival. However, the percentage of infants surviving without severe morbidity was low particularly at 23 weeks ( $1 \%$ of all births). In contrast, at
25 weeks gestation where the initiation of active treatment had not been shown to vary, there was no evidence of a difference in the survival between countries and 52\% of all births survived to discharge (figure 1D). For those surviving without severe morbidity, there was variation between countries in the proportion with BPD or no reported morbidity, with high rates of BPD in the UK.

\section{DISCUSSION}

Our study shows that international variation exists in the recording of live births and levels of intervention, suggesting differences in the initiation of early medical treatment for extremely preterm births between countries. This variation had a varying impact on survival outcomes by gestation and birth weight.

We have shown variation in the recording of births as live born at 23 and 24 weeks. This may relate to real differences in the percentage of births that are live born; or artefactual differences due to variation in the criteria used to decide whether a birth is viable. This will have an impact on observed neonatal mortality rates which are based on live births only, a problem highlighted elsewhere. ${ }^{11} 18$ Since the outcomes of these births are relatively poor, countries where there is a high percentage of births at this gestation recorded as live born will have an inflated rate of neonatal mortality compared with those where more births are recorded as stillborn. This finding emphasises the need to use perinatal mortality rates when comparing outcomes for births at this gestation or to introduce a gestational age threshold to prevent inappropriate comparisons.

Our findings suggested that for births of 23 and 24 weeks gestation weighing over $500 \mathrm{~g}$, there was significant variation in the levels of respiratory support provided and survival was higher in those countries with higher levels of intervention, although this was not formally tested. In this group, survival rates appear to be determined partially by the implementation of management guidelines, as shown by corroborating studies. ${ }^{10} 14$ However, while survival rates were improved in this group for those with high levels of intervention, rates of survival free of severe morbidity were low. This raises important questions concerning the long-term outcomes of these infants and the burden versus benefits balance over the decision to provide intensive treatment. Only for babies born at 25 weeks gestation was there no evidence of international variation in respiratory support initiation or survival. This finding shows a shift in the gestational age at which variation is most pronounced since 10 years ago when Kollee $e t a l^{19}$ found the widest variation in intervention rates across Europe was at 24 and 25 weeks gestation and suggests a 


\section{A: 22 weeks gestation}
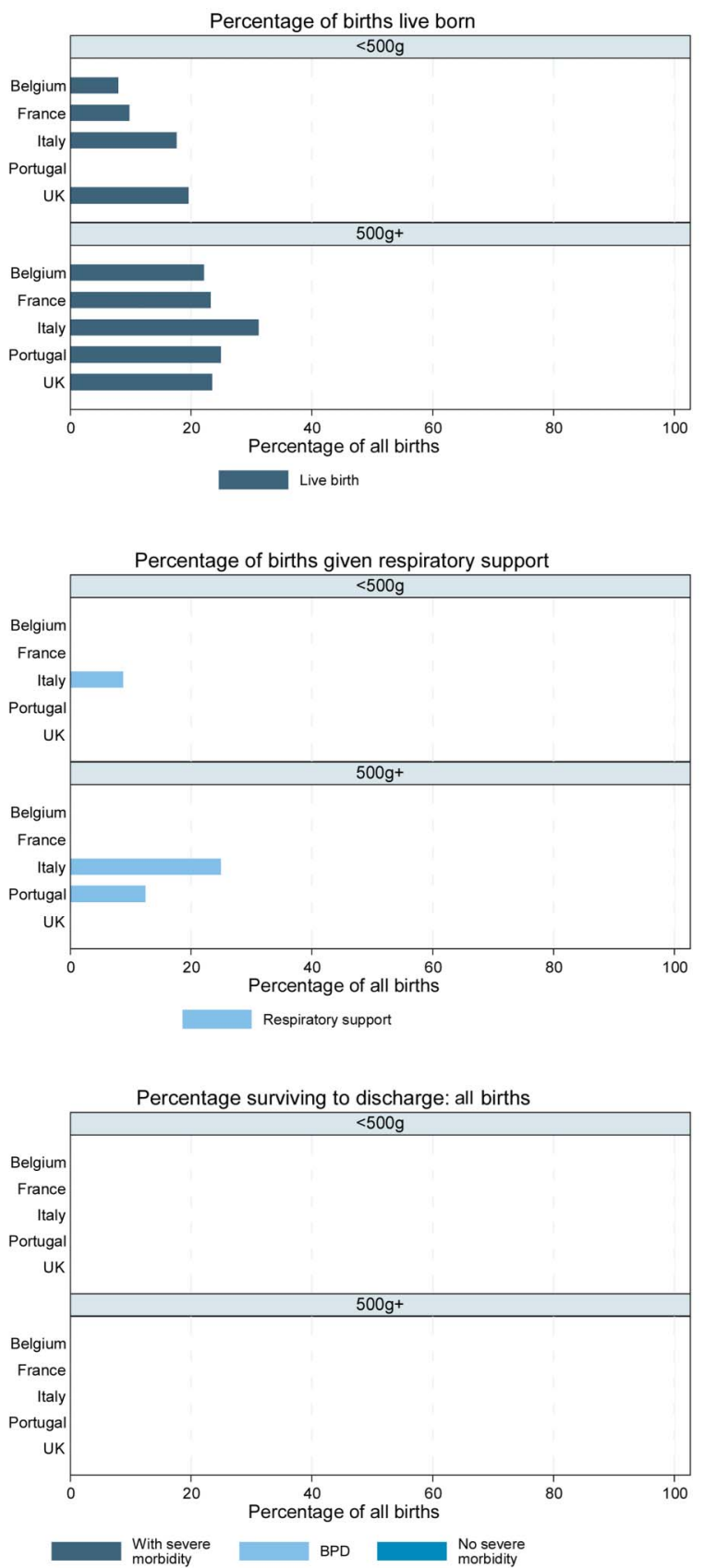

\section{B: 23 weeks gestation}
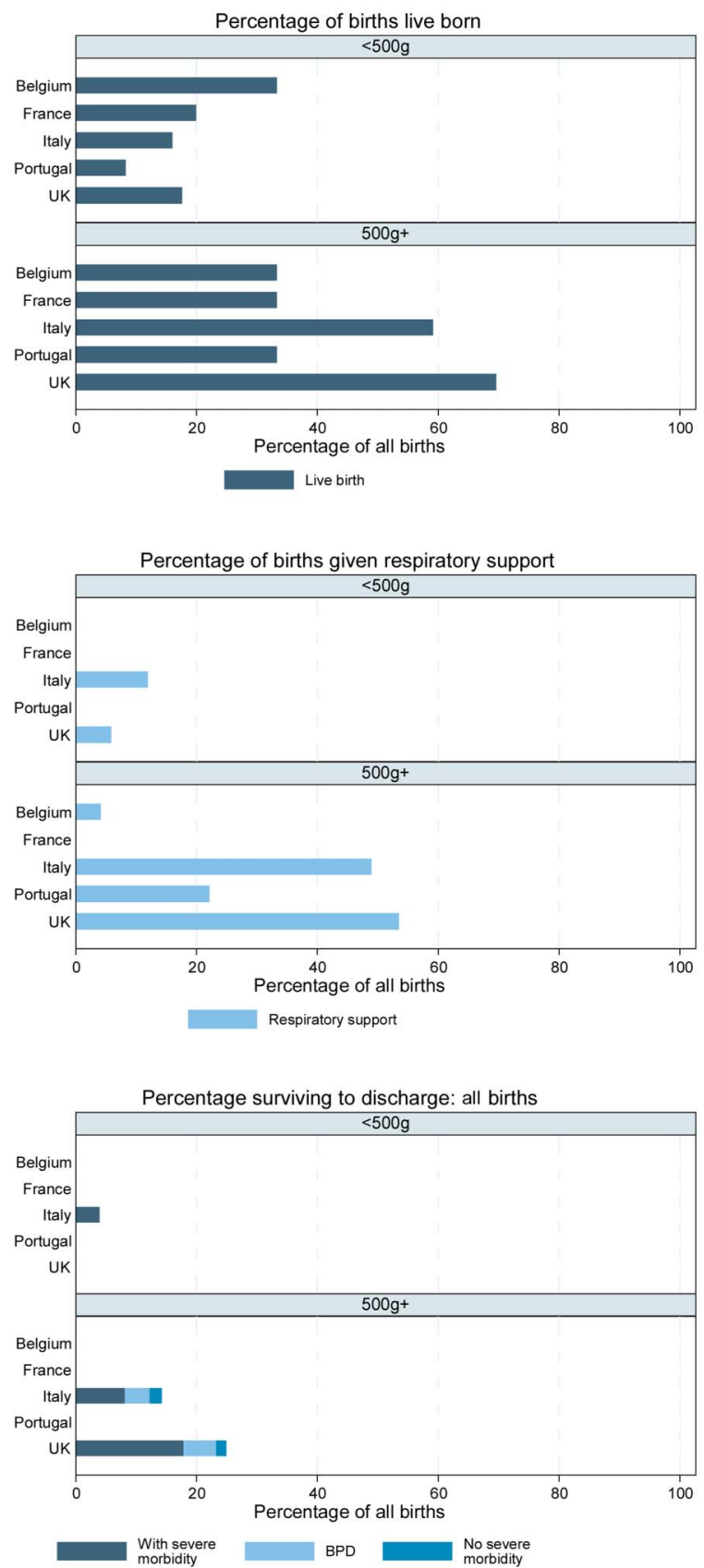

Figure 1 Percentage of births live born, percentage given respiratory support and percentage surviving to discharge by gestational age and birth weight in 5 European countries (based on data from 12 regions). A: 22 weeks gestation; B: 23 weeks gestation; C: 24 weeks gestation; D: 25 weeks gestation. Note: regions comprise: Belgium (Flanders); France (Burgundy, Ile-de-France, Northern); Italy (Emilia Romagna, Lazio, Marche); Portugal (Northern region, Lisbon); UK (East Midlands, Northern, Yorkshire). BPD, bronchopulmonary dysplasia.

gestational age change in the perception of viability. The provision of respiratory support varied for babies weighing $<500 \mathrm{~g}$. However for these babies, survival was universally poor with those countries having higher levels of intervention seeing no evidence of improved outcomes. This confirms the findings of studies of preterm babies born with extreme growth restriction. ${ }^{20}$ However, the level of care provided for these infants may be high and raise false hope for parents regarding their baby's chance of survival.

The Nuffield Council ${ }^{21}$ and American Academy of Pediatrics ${ }^{8}$ guidelines highlight that generally there is a consistent approach to extremely low birth weight and gestational age births and similarly at higher gestations and birth weights but in between a 'grey area' where survival is possible but infrequent and accompanied by a high risk of severe morbidity. We found this grey area differed between countries, with wide international variation in practice and outcomes, suggesting differences in whether birth weight or gestational age or both are used to determine management. Italy had a much lower threshold for the initiation of intensive care than other countries, while France had the highest threshold. These differences in intervention levels across countries are in agreement with previous studies and are likely to reflect variation in providers' attitudes ${ }^{22}$ and in guidelines on management. ${ }^{23-25}$ Recent research has questioned the ethical implications of basing life and death decisions only on gestational age before 25 weeks in France. ${ }^{26}$ 


\section{Original article}

\section{C: 24 weeks gestation}
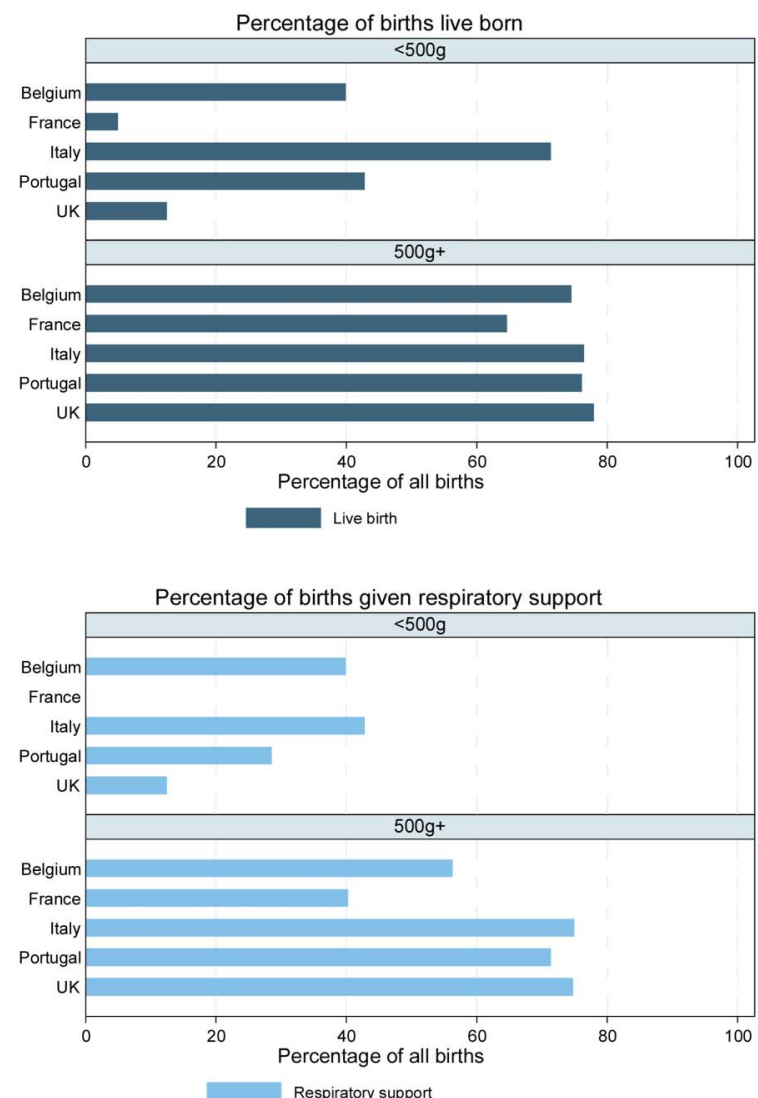

Respiratory support

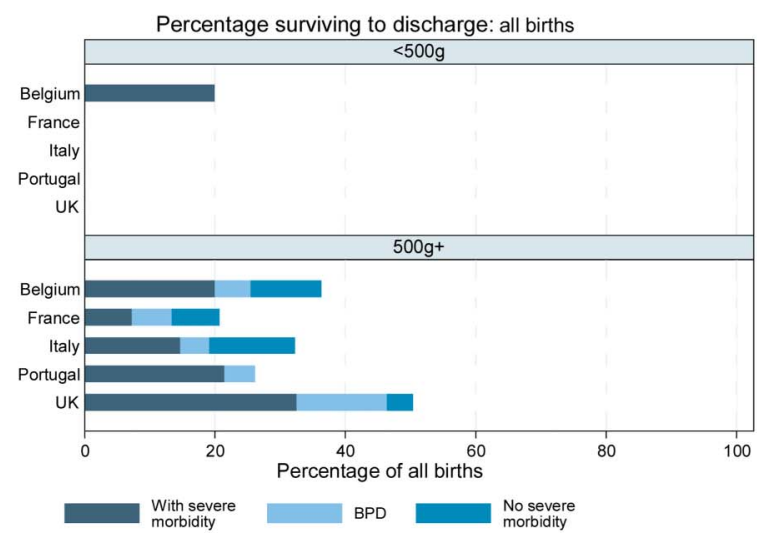

Figure 1 Continued

Factors that drive guideline development in ethically and emotionally sensitive areas of clinical practice are difficult to quantify, but variation is likely to reflect local differences in religious and cultural values as well as the legal environment, ${ }^{24}$ and personal experiences of the healthcare professionals. These different values and national contexts will influence perceptions of fetal viability and outcomes, ${ }^{27}$ and of concepts of 'disability' and 'quality of life' and 'best interests'. Other influential factors may be of a more practical nature, such as differences in eligibility of maternity and paternity pay or costs of funeral and burial arrangements. France and Belgium have high burial costs to parents for neonatal deaths but not stillbirths at these early gestations, which could influence the low number of babies being declared live born in these countries to help parents avoid these costs (CIRCULAIRE DHOS/DGS/DACS/DGCL n 2001/ 576 du 30 novembre 2001, http://social-sante.gouv.fr/fichiers/

\section{D: 25 weeks gestation}
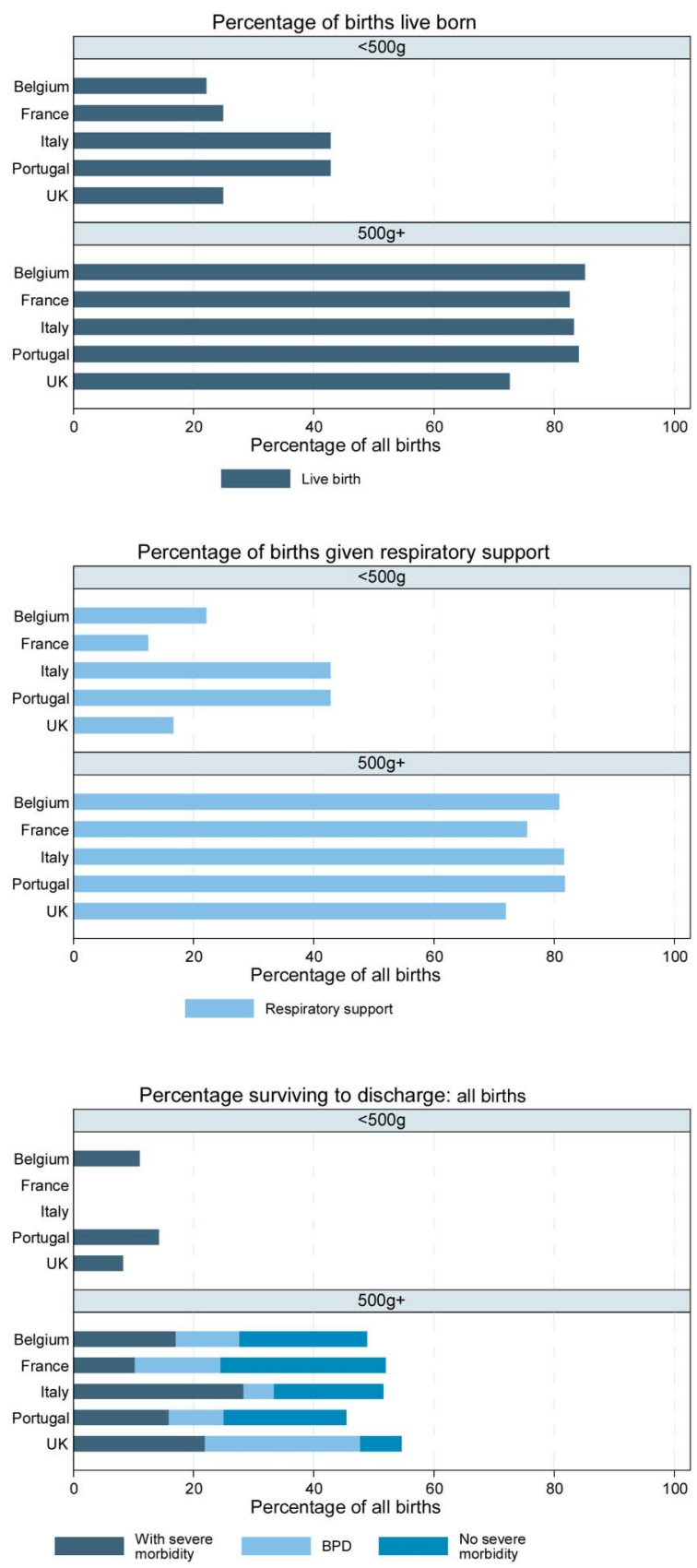

bo/2001/01-50/a0503302.htm; accessed 10/03/2016). In contrast in the UK, there is no assistance for parents of stillbirths before 24 weeks gestation and so a higher rate of live births at this gestation would enable greater access to maternity benefits (https://www.gov.uk/maternity-pay-leave/eligibility; accessed 01/ 03/2016), while in France benefits are provided regardless of whether the baby is live born or stillborn after 22 weeks gestation.

\section{Strengths and limitations of the study}

International comparisons of mortality using official birth and death registrations are limited by the differential practices regarding registration criteria. ${ }^{11}$ The strength of this study is the use of consistently recorded, locally collected international data on all stillbirths and live births from 22 to 25 weeks gestation irrespective of national official registration rules, babies allowing 


\begin{tabular}{|c|c|c|c|c|c|c|c|c|c|c|c|c|c|c|c|c|c|}
\hline & & & & \multicolumn{7}{|l|}{$<500 \mathrm{~g}$} & \multicolumn{7}{|l|}{$\geq 500 \mathrm{~g}$} \\
\hline & & \multicolumn{2}{|l|}{ Outcome } & Belgium & France & Italy & Portugal & UK & All & $\mathrm{p}$ Value & Belgium & France & Italy & Portugal & UK & All & $\mathrm{p}$ Value \\
\hline \multirow[t]{7}{*}{22 weeks gestation } & Births & & N (all births) & 25 & 61 & 34 & 20 & 56 & 196 & - & 27 & 30 & 16 & 8 & 17 & 98 & - \\
\hline & & & N (live births) & 2 & 6 & 6 & 0 & 11 & 25 & - & 6 & 7 & 5 & 2 & 4 & 24 & - \\
\hline & & & $\%$ live born & 8 & 10 & 18 & 0 & 20 & 13 & 0.135 & 22 & 23 & 31 & 25 & 24 & 25 & 0.973 \\
\hline & Active treatment & Antenatal steroids & \% (all births) & 4 & 0 & 3 & 0 & 5 & 2 & 0.489 & 0 & 0 & 25 & 13 & 0 & 5 & 0.002 \\
\hline & & Respiratory support & \% (all births) & 0 & 0 & 9 & 0 & 0 & 2 & 0.006 & 0 & 0 & 25 & 13 & 0 & 5 & 0.001 \\
\hline & Survival to discharge & Any survival & \% (all births) & 0 & 0 & 0 & 0 & 0 & 0 & - & 0 & 0 & 0 & 0 & 0 & 0 & - \\
\hline & & Morbidity free & \% (all births) & 0 & 0 & 0 & 0 & 0 & 0 & & 0 & 0 & 0 & 0 & 0 & 0 & \\
\hline \multirow[t]{7}{*}{23 weeks gestation } & Births & & N (all births) & 9 & 25 & 25 & 12 & 17 & 88 & - & 24 & 75 & 49 & 18 & 56 & 222 & - \\
\hline & & & N (live births) & 3 & 5 & 4 & 1 & 3 & 16 & - & 8 & 25 & 29 & 6 & 39 & 107 & - \\
\hline & & & $\%$ live born & 33 & 20 & 16 & 8 & 18 & 18 & 0.679 & 33 & 33 & 59 & 33 & 70 & 48 & $<0.001$ \\
\hline & Active treatment & Antenatal steroids & $\%$ (all births) & 11 & 10 & 21 & 8 & 29 & 16 & 0.500 & 4 & 0 & 58 & 33 & 58 & 31 & $<0.001$ \\
\hline & & Respiratory support & $\%$ (all births) & 0 & 0 & 12 & 0 & 6 & 5 & 0.243 & 4 & 0 & 49 & 22 & 54 & 27 & $<0.001$ \\
\hline & Survival to discharge & Any survival & \% (all births) & 0 & 0 & 4 & 0 & 0 & 1 & 0.636 & 0 & 0 & 14 & 0 & 25 & 9 & $<0.001$ \\
\hline & & Morbidity free & \% (all births) & 0 & 0 & 0 & 0 & 0 & 0 & & 0 & 0 & 2 & 0 & 2 & 1 & \\
\hline \multirow{7}{*}{24 weeks gestation } & Births & & N (all births) & 5 & 20 & 7 & 7 & 16 & 55 & - & 55 & 82 & 68 & 42 & 123 & 370 & - \\
\hline & & & N (live births) & 2 & 1 & 5 & 3 & 2 & 13 & - & 41 & 53 & 52 & 32 & 96 & 274 & - \\
\hline & & & $\%$ live born & 40 & 5 & 71 & 43 & 13 & 24 & 0.003 & 75 & 65 & 77 & 76 & 78 & 74 & 0.275 \\
\hline & Active treatment & Antenatal steroids & \% (all births) & 40 & 22 & 71 & 57 & 50 & 43 & 0.179 & 60 & 50 & 74 & 81 & 77 & 68 & $<0.001$ \\
\hline & & Respiratory support & \% (all births) & 40 & 0 & 43 & 29 & 13 & 16 & 0.033 & 56 & 40 & 75 & 71 & 75 & 64 & $<0.001$ \\
\hline & Survival to discharge & Any survival & $\%$ (all births) & 20 & 0 & 0 & 0 & 0 & 2 & 0.037 & 36 & 21 & 32 & 26 & 50 & 36 & $<0.001$ \\
\hline & & Morbidity free & \% (all births) & 0 & 0 & 0 & 0 & 0 & 0 & & 11 & 7 & 13 & 0 & 4 & 7 & \\
\hline \multirow{7}{*}{25 weeks gestation } & Births & & N (all births) & 9 & 8 & 7 & 7 & 12 & 43 & - & 47 & 98 & 60 & 44 & 128 & 377 & - \\
\hline & & & N (live births) & 2 & 2 & 3 & 3 & 3 & 13 & - & 40 & 81 & 50 & 37 & 93 & 301 & - \\
\hline & & & $\%$ live born & 22 & 25 & 43 & 43 & 25 & 30 & 0.810 & 85 & 83 & 83 & 84 & 73 & 80 & 0.175 \\
\hline & Active treatment & Antenatal steroids & $\%$ (all births) & 22 & 0 & 57 & 43 & 50 & 34 & 0.138 & 55 & 68 & 76 & 80 & 78 & 72 & 0.027 \\
\hline & & Respiratory support & $\%$ (all births) & 22 & 13 & 43 & 43 & 17 & 26 & 0.483 & 81 & 76 & 82 & 82 & 72 & 77 & 0.470 \\
\hline & Survival to discharge & Any survival & \% (all births) & 11 & 0 & 0 & 14 & 8 & 7 & 0.741 & 49 & 52 & 52 & 45 & 55 & 52 & 0.863 \\
\hline & & Morbidity free & $\%$ (all births) & 0 & 0 & 0 & 0 & 0 & 0 & & 21 & 28 & 18 & 20 & 7 & 18 & \\
\hline
\end{tabular}

Please note: regions comprise: Belgium (Flanders); France (Burgundy, Ile-de-France, Northern); Italy (Emilia Romagna, Lazio, Marche); Portugal (Northern region, Lisbon); UK (East Midlands, Northern, Yorkshire). 
for valid comparisons across countries. Many other studies of active management only focus on live births and this can severely bias the survival rates where there is a differential approach to whether a birth is reported as live born or not. By undertaking analyses using all births as a denominator, we have been able to explore in more detail the impact of perceived viability and active management on outcomes. We believe this cohort of births to be broadly representative of births occurring in the five countries whose data are analysed here. A standardised questionnaire was used to collect data from the medical records in obstetric and neonatal units with common pretested definitions. However, this limited the number of measures of both perceived viability and interventions included in the study. We analysed outcomes by gestation and birth weight alone and could not explore other factors which may influence clinicians' perceptions of viability such as the baby's physical appearance, response to first treatment or parental preferences. Intervention measures such as provision of antenatal steroids and respiratory support are limited in their scope but adequately reflect policies and general attitude of units towards viability and intention to treat prior to and following birth. It is possible the lack of administration of antenatal steroids may be due to organisational aspects of care such as limited time between the start of care during labour and delivery but this is unlikely to vary significantly between countries. Before delivery, obstetricians and neonatologists frequently use estimated fetal weights to determine potential viability and decisions around management in addition to gestational age. In this study, we were restricted to using birth weight which is not known until birth. Research is needed to assess whether both estimated fetal weight and birth weight contribute to the management decisions seen here.

\section{Implications for policy}

Preterm birth survival rates are widely used for counselling parents, decisions to initiate treatment and making international comparisons of care. The variation seen here in international survival rates of extremely preterm births make these decisions more challenging. Furthermore, our findings support the assertion made by Lantos and Meadow's ${ }^{14}$ that while protocols are frequently agreed based on survival rates, their implementation also determine survival rates since the withholding of intensive care leads to a perpetuation of poor survival. In our study, however this only seemed to be true for some gestational age and birthweight combinations. Variations in practice also have a major impact on the associated economic costs of each birth. While the numbers of births at these gestations are low, the length of stay and care provision can be extremely high and future long-term needs are uncertain.

Most guidelines on the early management of very preterm births focus on gestational age only, without considering birth weight (18). Until recently, the American Academy of Pediatrics Neonatal Resuscitation Programme ${ }^{8}$ recommended that resuscitation should be withheld when the gestational age is $<23$ weeks or a birth weight of $<400 \mathrm{~g}$, but this has now been amended to recommend that resuscitation should be withheld only <22 weeks (http://www2.aap.org/nrp/docs/15535_NRP\% 20Guidelines\%20Flyer_English_FINAL.pdf; accessed 22/03/ 2016) on the basis of improved reported survival in some countries. $^{28} 29$ Our findings support a higher gestational age criteria of 23 weeks, and also suggest the importance of a birthweight threshold. This is particularly relevant, since the exact assessment of gestational age has in most cases a margin of imprecision that may be crucial to management at 22-24 weeks gestation. Clinical estimates of birth weight in the delivery room may be inaccurate, and weighing a baby could delay resuscitation and impact on survival. However, birth weight is routinely measured at admission to the neonatal unit, and its prognostic value for infants of borderline viability suggests that it can be a useful criterion in counselling parents and in decisions about continuation of intensive treatment.

Collaborators EPICE Research Group: Belgium: Flanders (E Martens, G Martens, P Van Reempts); Denmark: Eastern Region (K Boerch, A Hasselager, L Huusom, 0 Pryds, T Weber); Estonia (L Toome, H Varendi); France: Burgundy, lle-de France and Northern region (PY Ancel, B Blondel, A Burguet, PH Jarreau, P Truffert); Germany: Hesse (RF Maier, B Misselwitz, S Schmidt), Saarland (L Gortner); Italy: Emilia Romagna (D Baronciani, G Gargano), Lazio (R Agostino, D DiLallo, F Franco), Marche (V Carnielli), M Cuttini; The Netherlands: Eastern and Central (C Koopman-Esseboom, A van Heijst, J Nijman); Poland: Wielkopolska ( J Gadzinowski, J Mazela); Portugal: Lisbon and Tagus Valley (LM Graça, MC Machado), Northern region (Carina Rodrigues, T Rodrigues), H Barros; Sweden: Stockholm (AK Bonamy, M Norman, E Wilson); UK: East Midlands and Yorkshire and Humber (E Boyle, ES Draper, BN Manktelow), Northern region (AC Fenton, DWA Milligan); Inserm, Paris (J Zeitlin, M Bonet, A Piedvache).

Acknowledgements We would like to acknowledge the participation of the Departments of Obstetrics and Neonatology from the following hospitals in the Effective Perinatal Intensive Care in Europe regions: Belgium (Flanders): ASZ Campus Geraardsbergen, Geraardsbergen; AZ Sint Maarten, Campus Zwartzustervest, Mechelen; AZ Sint Lucas, Assebroek; AZ Heilige Familie, Rumst-Reet; Sint Jozefskliniek, Izegem; AZ Sint Jozef, Malle; Sint Augustinus-MISA, Wilrijk; Onze Lieve Vrouwziekenhuis Campus Asse, Asse; AZ Diest, Diest; AZ Zeno Campus Knokke-Heist, Knokke-Heist; AZ Groeninge, Kortrijk; Sint Jozefkliniek-Campus Bornem, Bornem; Sint Vincentiusziekenhuis, Deinze; Maria Middelares, Gent; AZ Oudenaarde, Oudenaarde; AZ Glorieux, Ronse; AZ Delta Campus Menen, Menen; AZ Sint Elisabeth, Zottegem; ZOL_Campus Sint Jan, Genk; Jessa Ziekenhuis Campus Virga Jesse, Hasselt; Sint Franciskusziekenhuis, Heusden-Zolder; Maria Ziekenhuis Noord-Limburg, Overpelt; Sint Trudoziekenhuis, Sint-Truiden; AZ Damiaan, Oostende; AZ Sint Lucas, Gent; AZ Sint Blasius, Dendermonde; AZ Delta Campus Wilgenstraat, Roeselare; UZ Brussel, Brussel; ZNA Jan Palfijn, Merksem; Sint Andriesziekenhuis, Tielt; ZNA Middelheim, Antwerpen; Imeldaziekenhuis, Bonheiden; AZ Sint Maarten—Campus Duffel, Duffel; AZ KLINA, Brasschaat; AZ Jan Portaels, Vilvoorde; Universitair Ziekenhuis Antwerpen, Edegem; UZ Leuven Campus Gasthuisberg, Leuven; UZ Gent, Gent; Sint Vincentiusziekenhuis-Campus Sint Jozef, Mortsel; AZ Alma, Eeklo; AZ Turnhout, Turnhout; Heilig Hartziekenhuis, Mol; AZ Sint Jan Campus Henri Serruys, Oostende; Ziekenhuis Maas \& Kempen, Bree; Sint Vincentius Ziekenhuis, Antwerpen; AZ Vesalius-Campus Sint Jacobus, Tongeren; ASZ-Campus Aalst, Aalst; Onze Lieve Vrouwziekenhuis-Campus Aalst, Aalst; AZ Delta Campus Stedelijk Ziekenhuis, Roeselare; AZ Sint Rembert, Torhout; AZ Monica-Campus Deurne, Deurne; AZ Lokeren, Lokeren; Jan

Ypermanziekenhuis, leper; AZ Sint Elisabeth, Herentals; AZ Sint Jan, Brugge; AZ Jan Palfijn, Gent; AZ Sint Augustinus Veurne, Veurne; RZ Sint Maria, Halle; Heilig Hart Ziekenhuis, Leuven; AZ Nikolaas-Campus SM, Sint-Niklaas; Onze Lieve Vrouw van Lourdes Ziekenhuis Waregem vzW, Waregem; ACZA Ziekenhuis-Campus Sint Erasmus, Borgerhout; Heilig Hart, Lier; AZ Sint Dimpna, Geel; Heilig Hart, Tienen. France (Burgundy): $\mathrm{CH}$ d'Autun, Autun; $\mathrm{CH}$ Auxerre, Auxerre; $\mathrm{CH}$ de Beaune, Beaune; CH William Morey, Chalon Sur Saone; Clinique de Cosne-Sur-Loire, Cosne-Sur-Loire; CH de Decize, Decize; CHU Le Bocage-Hôpital D'enfants, Dijon; Clinique Sainte-Marthe, Dijon; Site Hospitalier Foch, Le Creusot; CH Les Chanaux, Macon; $\mathrm{CH}$ de Nevers, Nevers; CH Les Charmes, Paray Le Monial; $\mathrm{CH}$ de Semur-En-Auxois, Semur En Auxois; CH de Sens, Sens; France (Ile-de-France): Hôpital Prive D’Antony, Antony; CH Victor Dupouy, Argenteuil; CH Arpajon, Arpajon; Hôpital Prive D’Athis-Mons, Athis-Mons; Hôpital Européen La Roseraie, Aubervilliers; CHI Robert Ballanger, Aulnay Sous-Bois; CH Intercommunal Des Portes de L'Oise, Beaumont Sur Oise; CHU Jean Verdier, Bondy; Clinique Ambroise Paré, Bourg-La-Reine; Hôpital Privé de Marne Chantereine, Brou Sur Chantereine; Hôpital Prive de Marne La Vallée, Bry Sur Marne; Hôpital Saint-Camille, Bry Sur Marne; Clinique de Champigny-Hôpital Paul D’Egine, Champigny Sur Marne; Hôpital Antoine Béclère, Clamart; Hôpital Beaujon, Clichy; CH Louis Mourier, Colombes; Clinique Du Parisis, Cormeilles-En-Parisis; CH René Arbeltier, Coulommiers; CHI Créteil, Créteil; Clinique Claude Bernard, Ermont; CH Sud Essonne, EtampesDourdan; CH Louise Michel, Evry; Clinique de L'Essonne Evry, Evry; CMO D'Evry, Evry; Polyclinique de La Forêt, Fontainebleau; CH Fontainebleau, Fontainebleau; CH de Gonesse, Gonesse; Clinique Lambert, La Garenne-Colombes; CHG de Marne La Vallée, Lagny; Hôpital Prive de Seine-Saint-Denis, Le Blanc Mesnil; CH de Versailles-André Mignot, Le Chesnay; Hôpital Prive de Parly 2 Le Chesnay, Le Chesnay; CHU Kremlin Bicêtre, Le Kremlin-Bicêtre; Maternité Des Lilas, Les Lilas; Institut Hospitalier Franco-Britannique, Levallois Perret; Clinique Conti, L'Isle-Adam; Polyclinique Vauban, Livry Gargan; Clinique de L'Yvette, Longjumeau; CH de Longjumeau, Longjumeau; CH Mantes La Jolie, Mantes La Jolie; Hôpital Prive Jacques Cartier, Massy; CH de Meaux, Meaux; CH Marc Jacquet, Melun; 
Polyclinique Saint Jean, Melun; Clinique de Meudon La Foret, Meudon La Foret; $\mathrm{CH}$ Intercommunal de Meulan-Les Mureaux, Meulan-En-Yvelines; CH de Montereau, Montereau; CHI Le Raincy-Montfermeil, Montfermeil; Groupe Hospitalier Eaubonne-Montmorency, Montmorency; CHI André Grégoire, Montreuil; Hôpital Max Fourestier, Nanterre; CH Neuilly Courbevoie, Neuilly Sur Seine; Hôpital Américain, Neuilly Sur Seine; Clinique Sainte-Isabelle, Neuilly-Sur-Seine; Hôpital Prive Armand Brillard, Nogent Sur Marne; CH D'Orsay, Orsay; Clinique de La Muette, Paris; Clinique Jeanne D'arc, Paris; Clinique Leonard de Vinci, Paris; Clinique Sainte Thérèse, Paris; Clinique Saint-Louis, Paris; GH Armand Trousseau—La Roche-Guyon, Paris; GH Diaconesses Croix St Simon, Paris; GH Pitié-Salpêtrière, Paris; GH Saint Joseph/Notre Dame de Bon-Secours, Paris; GIH Bichat/Claude Bernard, Paris; Hôpital Cochin-Port Royal, Paris; Hôpital Lariboisière, Paris; Hôpital Les Bluets, Paris; Hôpital Necker, Paris; Hôpital Robert Debré, Paris; Hôpital Saint-Antoine, Paris; Hôpital Tenon, Paris; Institut de Puériculture Et de Périnatalogie, Paris; Institut Mutualiste Montsouris, Paris; Maternité Sainte-Félicité, Paris; CHI Poissy/Saint-Germain-En-Laye, Poissy; CH René Dubos, Pontoise; Centre Hospitalier Léon Binet, Provins; Hôpital Prive Claude Galien, Quincy-Sous-Sénart; CH de Rambouillet, Rambouillet; Clinique Les Martinets, Rueil-Malmaison; CH Des Quatre Villes, Saint Cloud; CH de Saint Denis, Saint Denis; Hôpital Esquirol St Maurice, Saint Maurice; Clinique Saint Germain, Saint-Germain-En-Laye; Hôpital Prive Nord Parisien, Sarcelles; CH Des Quatre Villes, Sèvres; Hôpital Militaire Begin, St Mande; Clinique Gaston Métivet, St Maur Des Fosses; Clinique de L'Estrées, Stains; Hôpital Foch, Suresnes; Clinique de Tournan, Tournan-En-Brie; Hôpital Prive de L'Ouest Parisien, Trappes; Clinique Du Vert-Galant, Tremblay En France; Hôpital Prive de Versailles-Franciscaines, Versailles; CH Intercommunal, Villeneuve Saint Georges; Clinique Les Noriets, Vitry Sur Seine; France (Northern region): CH D'Armentières, Armentières; CH D'Arras, Arras; Clinique Bon-Secours, Arras; CH de Béthune, Béthune; Clinique Anne D'Artois, Béthune; CH de Boulogne-Sur-Mer, Boulogne Sur Mer; CH de Calais, Calais; CH de Cambrai, Cambrai; Polyclinique Sainte-Marie, Cambrai; CH de Denain, Denain; Polyclinique de La Clarence, Divion; $\mathrm{CH}$ de Douai, Douai; Polyclinique Villette, Dunkerque; $\mathrm{CH}$ de Fourmies, Fourmies; GCS Flandre Maritime, Grande Synthe; CH D'hazebrouck, Hazebrouck; CH de La Région de St Omer, Helfaut; Clinique Saint-Amé, Lambres-Les-Douai; CH du Cateau, Le Cateau Cambrésis; CH de Lens, Lens; Polyclinique de Riaumont de Lievin, Lievin; GHI CL St-Vincent de Paul, Lille; Hôpital Jeanne de Flandre, Lille; Pavillon Du Bois, Lille; CH Sambre-Avesnois, Maubeuge; Polyclinique Du Val de Sambre, Maubeuge; CHAM Site Principal, Rang Du Fliers; Maternité Paul Gellé, Roubaix; CH de Seclin, Seclin; Centre Médical Chirurgical Obstétrical Côte d'Opale, St Martin/Boulogne; Clinique Maternité du Parc, St Saulve; Clinique Du Val de Lys, Tourcoing; Hôpital Guy Chatiliez, Tourcoing; CH de Valenciennes, Valenciennes; Nouvelle Clinique Villeneuve D' Ascq, Villeneuve d'Ascq. Italy (Emilia Romagna): Azienda Ospedaliero-universitaria di Modena, Modena; Azienda Ospedaliero-universitaria di Bologna, Bologna; Ospedale Maggiore C.A. Pizzardi, Bologna; Azienda Ospedaliera di Reggio Emilia, Reggio Emilia; Azienda Ospedaliero-universitaria di Parma, Parma; Ospedale Infermi, Rimini; Ospedale M. Bufalini, Cesena; Azienda Ospedaliero-universitaria di Ferrara, Ferrara; Ospedale Santa Maria delle Croci, Ravenna; Ospedale Morgagni—Pierantoni, Forli; Ospedale Guglielmo da Saliceto, Piacenza; Ospedale Civile Nuovo Santa Maria della Scaletta, Imola; Ospedale Degli Infermi, Faenza; Ospedale Santa Maria Bianca, Mirandola; Ospedale Civile Guastalla, Guastalla; Ospedale SS. Annunziata, Cento; Ospedale Umberto I, Lugo; Ospedale Unico della Val D'Arda, Fiorenzuola D'Arda; Ospedale San Secondo, Fidenza; Ospedale B. Ramazzini, Carpi; Ospedale Pavullo nel Frignano, Pavullo nel Frignano; Nuovo Ospedale Civile di Sassuolo, Sassuolo; Ospedale di Bentivoglio, Bentivoglio. Italy (Lazio Region): Policlinico Umberto I; Policlinico A. Gemelli; Azienda Ospedaliera San Camillo; Azienda Ospedaliera San Giovanni; Azienda Ospedaliera San Filippo Neri; Ospedale Pediatrico Bambino Gesù; Ospedale Belcolle-Viterbo; Ospedale Sant'Eugenio; Ospedale SG Calibita Fatebenefratelli; Ospedale S. Pietro Fatebenefratelli; Policlinico Casilino. Italy (Marche): Azienda Ospedaliero-universitaria Ospedali Riuniti Umberto I-G.M. Lancisi-G. Salesi, Ancona; Ospedale Generale Provinciale C.G. Mazzoni, Ascoli Piceno; Ospedale Generale Provinciale Macerata, Macerata; Azienda Ospedaliera San Salvatore, Pesaro; Ospedale A. Murri, Fermo; Ospedali Riuniti di Jesi, Jesi; Ospedale Civile E. Profili, Fabriano; Ospedale Santa Croce, Fano. Portugal (Northern region); Centro Hospitalar de Entre o Douro e Vouga, E.P.E.-Hospital de São Sebastião; Centro Hospitalar de Trás-os-Montes e Alto Douro, E.P.E.—Hospital São Pedro; Centro Hospitalar de Vila Nova de Gaia/Espinho, E.P.E.—Unidade II; Centro Hospitalar do Alto Ave, E.P.E.—Unidade de Guimarães; Centro Hospitalar do Médio Ave, E.P.E.— Unidade de Famalicão; Centro Hospitalar do Porto, E.P.E.Maternidade Júlio Dinis; Centro Hospitalar do Tâmega e Sousa, E.P.E.-Hospital Padre Américo; Centro Hospitalar Póvoa de Varzim-Vila do Conde, E.P.E.Unidade da Póvoa de Varzim; Centro Hospitalar São João, E.P.E.-Hospital São João; Hospital de Braga; Unidade Local de Saúde de Matosinhos, E.P.E.-Hospital Pedro Hispano; Unidade Local de Saúde do Alto Minho, E.P.E.- Hospital de Santa Luzia; Unidade Local de Saúde do Nordeste, E.P.E.—Unidade de Bragança. Portugal (Lisbon and Tagus Valley Region): Centro Hospitalar Barreiro Montijo, E.P.E.Hospital Nossa Senhora do Rosário; Centro Hospitalar de Lisboa Central, E.P.E.Hospital Dona Estefânia; Centro Hospitalar de Lisboa Central, E.P.E.-Maternidade Alfredo da Costa; Centro Hospitalar de Lisboa Ocidental, E.P.E.—Hospital de São Francisco Xavier; Centro Hospitalar de Setúbal, E.P.E.—Hospital São Bernardo;
Centro Hospitalar do Médio Tejo, E.P.E.- - Hospital Doutor Manoel Constâncio; Centro Hospitalar do Oeste-Unidade de Caldas da Rainha; Centro Hospitalar do Oeste-Unidade de Torres Vedras; Centro Hospitalar Lisboa Norte, E.P.E.—Hospital Santa Maria; Hospital Cuf Descobertas; Hospital da Luz; Hospital de Cascais Dr. José de Almeida; Hospital de Santarém, E.P.E.; Hospital Garcia de Orta, E.P.E.; Hospital Lusíadas Lisboa; Hospital Professor Doutor Fernando Fonseca, E.P.E.; Hospital Vila Franca de Xira. UK (Northern region): Royal Victoria Infirmary Newcastle upon Tyne; James Cook University Hospital Middlesbrough; North Tees University Hospital Stockton; Sunderland Royal Hospital; Wansbeck Hospital Ashington; Queen Elizabeth Hospital Gateshead; North Tyneside General Hospital; South Tyneside General Hospital; Cumberland Infirmary Carlisle; West Cumberland Infirmary. UK (East Midlands_-Yorkshire and Humber): Chesterfield Royal Hospital; Bassetlaw District General Hospital; Kings Mill Hospital; Royal Derby Hospital; Nottingham City Hospital; Nottingham Queen's Medical Centre; Lincoln County Hospital; Boston Pilgrim Hospital; University Hospitals of Leicester (LGH + LRI); Kettering General Hospital; Northampton General Hospital; Grimsby Diana Princess of Wales Hospital; Scunthorpe General Hospital; Barnsley District General Hospital; Rotherham District General Hospital; Doncaster Royal Infirmary; Jessop Wing Sheffield; Airedale District General Hospital; Bradford Royal Infirmary; Dewsbury District General Hospital; Halifax Calderdale Royal Infirmary; Harrogate District General Hospital; Hull Royal Infirmary; Leeds General Infirmary; Leeds St James's; Scarborough District General Hospital; York District Hospital; Wakefield Pinderfields General Hospital. All authors have completed the International Committee of Medical Journal Editors uniform disclosure form at http:/www.icmje.org/coi_ disclosure.pdf and have declared no support from any organisation for the submitted work (or describe if any); no financial relationships with any organisations that might have an interest in the submitted work in the previous 3 years (or describe if any), no other relationships or activities that could appear to have influenced the submitted work (or describe if any).

Contributors All authors contributed to the overall conception and design of the study. LKS wrote the first draft of this manuscript and analysed the data. All authors contributed to the interpretation of results and drafting of the manuscript. All authors read and approved the final manuscript. LKS is the guarantor. LKS affirms that the manuscript is an honest, accurate and transparent account of the study being reported; that no important aspects of the study have been omitted and that any discrepancies from the study as planned (and, if relevant, registered) have been explained.

Funding The research leading to these results received funding from the European Union's Seventh Framework Programme ((FP7/2007-2013)) under grant agreement $n^{\circ} 259882$. Additional funding was received in the following region: France (French Institute of Public Health Research/Institute of Public Health and its partners the French Health Ministry, the National Institute of Health and Medical Research, the National Institute of Cancer and the National Solidarity Fund for Autonomy; grant ANR-11-EQPX-0038 from the National Research Agency through the French Equipex Program of Investments in the Future and the PremUp Foundation). UK (funding for The Neonatal Survey from Neonatal Networks for East Midlands and Yorkshire and Humber regions). The funders had no role in study design; in the collection, analysis and interpretation of data; in the writing of the report or in the decision to submit the article for publication. LKS is funded by a National Institute for Health Research Career Development Fellowship. This article presents independent research funded by the National Institute for Health Research (NIHR). The views expressed are those of the authors and not necessarily those of the National Health Service, the NIHR or the Department of Health.

Competing interests None declared. All authors have completed the International Committee of Medical Journal Editors uniform disclosure form at http://www.icmje. org/coi_disclosure.pdf and have declared no support from any organisation for the submitted work (or describe if any); no financial relationships with any organisations that might have an interest in the submitted work in the previous 3 years (or describe if any), no other relationships or activities that could appear to have influenced the submitted work (or describe if any).

Ethics approval Parental consent and ethics and data protection approval was obtained in each study region as required by national legislation.

Provenance and peer review Not commissioned; externally peer reviewed.

Data sharing statement No additional data are available.

\section{REFERENCES}

1 Marlow N. Keeping up with outcomes for infants born at extremely low gestational ages. JAMA Pediatr 2015;169:207-8.

2 Ancel PY, Goffinet F, EPIPAGE 2 Writing Group. EPIPAGE 2: a preterm birth cohort in France in 2011. BMC Pediatr 2014;14:97.

3 Costeloe KL, Hennessy EM, Haider S, et al. Short term outcomes after extreme preterm birth in England: comparison of two birth cohorts in 1995 and 2006 (the EPICure studies). BMJ 2012;345:e7976. 


\section{Original article}

4 Kallen K, Serenius F, Westgren M, et al. Impact of obstetric factors on outcome of extremely preterm births in Sweden: prospective population-based observational study (EXPRESS). Acta Obstet Gynecol Scand 2015;94:1203-14.

5 Salihu HM, Salinas-Miranda AA, Hill L, et al. Survival of pre-viable preterm infants in the United States: a systematic review and meta-analysis. Semin Perinatol 2013;37:389-400.

6 Field DJ, Dorling JS, Manktelow BN, et al. Survival of extremely premature babies in a geographically defined population: prospective cohort study of 1994-9 compared with 2000-5. BMJ 2008;336:1221-3.

7 Chervenak FA, McCullough LB. Ethical issues in periviable birth. Semin Perinatol 2013;37:422-5.

8 Bell EF, American Academy of Pediatrics Committee on Fetus and Newborn. Noninitiation or withdrawal of intensive care for high-risk newborns. Pediatrics 2007;119:401-3.

9 Chauhan SP, Ananth CV. Periviable births: epidemiology and obstetrical antecedents. Semin Perinatol 2013;37:382-8.

10 Rysavy MA, Li L, Bell EF, et al., Eunice Kennedy Shriver National Institute of Child Health and Human Development Neonatal Research Network. Between-hospital variation in treatment and outcomes in extremely preterm infants. $N$ Engl J Med 2015;372:1801-11.

11 Joseph KS, Liu S, Rouleau J, et al. Influence of definition based versus pragmatic birth registration on international comparisons of perinatal and infant mortality: population based retrospective study. BMJ 2012;344:e746.

12 Mohangoo AD, Blondel B, Gissler M, et al., Euro-Peristat Scientific Committee. International comparisons of fetal and neonatal mortality rates in high-income countries: should exclusion thresholds be based on birth weight or gestational age? PLOS ONE 2013;8:e64869.

13 Gallagher K, Aladangady N, Marlow N. The attitudes of neonatologists towards extremely preterm infants: a Q methodological study. Arch Dis Child Fetal Neonatal Ed 2016;101:F31-6.

14 Lantos JD, Meadow W. Variation in the treatment of infants born at the borderline of viability. Pediatrics 2009;123:1588-90.

15 de Laat MW, Wiegerinck MM, Walther FJ, et al., Nederlandse Vereniging voor Obstetrie en Gynaecologie. Practice guideline 'Perinatal management of extremely preterm delivery'. Ned Tijdschr Geneeskd 2010;154:A2701.

16 Zeitlin J, Manktelow BN, Piedvache A, et al., EPICE Research Group. Use of evidence based practices to improve survival without severe morbidity for very preterm infants: results from the EPICE population based cohort. BMJ 2016;354: i2976.

17 Gortner L, Misselwitz B, Milligan D, et al., members of the MOSAIC Research Group. Rates of bronchopulmonary dysplasia in very preterm neonates in Europe: results from the MOSAIC cohort. Neonatology 2011;99:112-17.

18 Smith L, Draper ES, Manktelow BN, et al. Comparing regional infant death rates: the influence of preterm births $<24$ weeks of gestation. Arch Dis Child Fetal Neonatal Ed 2013:98:F103-7.

19 Kollee LA, Cuttini M, Delmas D, et al., MOSAIC Research group. Obstetric interventions for babies born before 28 weeks of gestation in Europe: results of the MOSAIC study. BJOG 2009;116:1481-91.

20 Kamoji VM, Dorling JS, Manktelow BN, et al. Extremely growth-retarded infants: is there a viability centile? Pediatrics 2006;118:758-63.

21 Nuffield Council on Bioethics. Critical care decisions in fetal and neonatal medicine: ethical issues. London, 2006

22 De Leeuw R, Cuttini M, Nadai M, et al., EURONIC study group. Treatment choices for extremely preterm infants: an international perspective. J Pediatr 2000;137:608-16.

23 Pignotti MS, Donzelli G. Perinatal care at the threshold of viability: an international comparison of practical guidelines for the treatment of extremely preterm births. Pediatrics 2008;121:e193-8.

24 Cuttini M, Casotto V, de Vonderweid U, et al., EURONIC Study Group. Neonatal end-of-life decisions and bioethical perspectives. Early Hum Dev 2009;85(10 Suppl): S21-5.

25 Guillen U, Weiss EM, Munson D, et al. Guidelines for the management of extremely premature deliveries: a systematic review. Pediatrics 2015;136:343-50.

26 Perlbarg J, Ancel PY, Khoshnood B, et al., Epipage-2 Ethics group. Delivery room management of extremely preterm infants: the EPIPAGE-2 study. Arch Dis Child Fetal Neonatal Ed 2016;101:F384-90.

27 Fanaroff JM, Hascoët JM, Hansen TW, et al., International Perinatal Collegium (IPC). The ethics and practice of neonatal resuscitation at the limits of viability: an international perspective. Acta Paediatr 2014;103:701-8.

28 Kyser $\mathrm{KL}$, Morriss FH Jr, Bell EF, et al. Improving survival of extremely preterm infants born between 22 and 25 weeks of gestation. Obstet Gynecol 2012;119:795-800.

29 Ishii N, Kono Y, Yonemoto N, et al., Neonatal Research Network, Japan. Outcomes of infants born at 22 and 23 weeks' gestation. Pediatrics 2013:132:62-71. 

European countries: a population-based cohort study

Lucy K Smith, Beatrice Blondel, Patrick Van Reempts, Elizabeth S

Draper, Bradley N Manktelow, Henrique Barros, Marina Cuttini and Jennifer Zeitlin

Arch Dis Child Fetal Neonatal Ed2017 102: F400-F408 originally published online February 23, 2017

doi: 10.1136/archdischild-2016-312100

Updated information and services can be found at:

http://fn.bmj.com/content/102/5/F400

\section{Notes}

\section{These include:}

References This article cites 28 articles, 12 of which you can access for free at: http://fn.bmj.com/content/102/5/F400\#ref-list-1

Email alerting Receive free email alerts when new articles cite this article. Sign up in the service box at the top right corner of the online article.

To request permissions go to:

http://group.bmj.com/group/rights-licensing/permissions

To order reprints go to:

http://journals.bmj.com/cgi/reprintform

To subscribe to BMJ go to:

http://group.bmj.com/subscribe/ 